\title{
Surgical Treatment of Canine Femoral Fractures - A Review
}

\author{
Lea Lovrić ${ }^{1 *}$, Mario Kreszinger ${ }^{2}$ and Marko Pećin ${ }^{2}$ \\ ${ }^{1}$ Department of Parasitology and Invasive Diseases with Clinic, Faculty of Veterinary Medicine, University of Zagreb, Heinzelova 55, Zagreb 10 000, Croatia \\ ${ }^{2}$ Surgery, Orthopaedics and Ophthalmology Clinic, Faculty of Veterinary Medicine, University of Zagreb, Heinzelova 55, Zagreb 10000 , Croatia \\ *Corresponding author's Email: lovric.lea@gmail.com; (D) ORCiD: 0000-0002-3246-7575
}

\begin{abstract}
Femoral fractures in dogs and cats account for 20-25\% of all fractures for which surgical treatment is a method of choice. Surgical treatment is based upon biological principle of open anatomic reduction and osteosynthesis. Arbeitsgemeinschaft für Osteosynthesefragen (AO) classification of fractures has a widespread use in general. Present study discusses different methods of osteosynthesis and healing process based on special cases managed in a certain small animal clinic in Hollabrunn, Austria, in 2016. The level of femoral fracture and the chosen method of osteosynthesis are shown respectively. According to available literature and authors' personal observations during externship period, the best results have been achieved using minimally invasive surgery. The surgical method choice depends on type, level and complexity of fracture, surgical skills and equipment of the team providing care respectively.
\end{abstract}

Keywords: Dog, Femur, Fracture, Osteosynthesis.

\section{INTRODUCTION}

Femoral fractures in dogs and cats include $20 \%-25 \%$ of all fractures. It is represented $45 \%$ of all long bone fractures, the percentage is doubled regarding all other bones individually (DeCamp et al., 2016). Traffic accident is the most common cause. Fractures may be also caused by shot injuries and bone disorders, mostly due to primary or metastatic tumors with consequent pathological fracture. Almost $86 \%$ of femoral fractures occur in animals younger than 5 years, whereas $48 \%$ appear in animals under the age of one year. Proximal and distal epiphyseal fractures happen in younger animals, whereas diaphyseal and metaphyseal fractures are more frequent in older animals (Guiot et al., 2012, Abd El Raouf, 2017). Fracture healing is influenced by many factors: biomechanical factors (postoperative fragment instability), the bone physiology (metabolic factors, importance of fracture hematoma) and anatomical factors (the type of fracture and deficient vascularization with possible vascular variations) (Perren, 2002; Kolar et al., 2010 Pan et al., 2019). Anatomy of the fracture is very well described in AO classification which is presented further in this text.

The significance of biological potential of the fracture hematoma is well known and important in the use of intramedullary nailing of the long bone fractures (Horstman et al., 2004; Schell et al., 2017). Due to inability to retain the fragments in anatomical position after fracture reduction, internal or external fixation is indicated, the choice of method depending on the fracture type respectively (DeCamp et al., 2016).

The goal of fracture treatment is to achieve final physiological function of the affected limb. To accomplish this aim the method of internal fixation can vary from intramedullary nailing/pinning (where the cellular potential of fracture hematoma has its importance) to plate application, thus including biological and mechanical benefit of the method chosen (Déjardin, 2020).

The objective of present retrospective study was to show cases of osteosynthesis of various types of femoral fractures in dogs and also results of osteosynthesis by 4-8 weeks post-surgical radiography. The data and radiographic images were used with special permission from the veterinary clinic, Tierklinik Hollabrun, Austria.

\section{MATERIALS AND METHODS}

In this retrospective study, medical records of eight dogs who sustained traumatic femoral fracture clinically managed and operated in 2016 at veterinary clinic "Tierklinik Hollabrun", Austria were used. Clinical examination was followed by radiological imaging in two projections: Medio-lateral and cranio-caudal, with mandatory imaging of contralateral limb. All patients were submitted to radiological imaging by digital x-ray machine preoperatively, immediately postoperatively, 4 weeks postoperatively and some of them 8 weeks after surgery. Radiological technique was designated for each patient $(60-70 \mathrm{kV}$ and 4-6 mAs) respectively. 
Selected cases were divided according to fracture type into three groups consecutively: proximal epiphyseal (A); diaphyseal (B) and distal epiphyseal (C). AO classification was applied, and Salter-Harris classification the same for epiphyseal fractures. AO classification uses alpha-numeric system to assess location and degree of the fracture. Number 3 denotes femur and is divided further numerically: number 1: for proximal epiphysis, number 2; for diaphysis, and number 3: for distal epiphysis. The letters denote fracture type: letter A: for single fracture, letter B: for fracture with free fragment, and letter C: for compound fracture. Each fracture type is denoted with number suffix from 1 to 3 describing the comminution (Rüedi and Murphy, 2000).

\section{Ethical approval}

This article is not experimental investigation, but retrospective review of management of accidentally injured patients with purpose of companion animals' welfare.

\section{RESULTS}

\section{Group A}

Case 1. AO: 31-B3

A 6-month-old Border Collie bitch, with $15.4 \mathrm{~kg}$ of body weight was injured in a car incursion and sustained Salter-Harris type I femoral head fracture. Through cranio-lateral incision, the hip capsule was opened and two parallel $1.2 \mathrm{~mm}$ Kirschner wires were positioned. 4 and 8 weeks post-operative radiographic follow up revealed good bone healing and restitution of full function. Pre- and postoperative radiographs are shown on figure 1.

\section{Case 2. AO: $31-B 3$}

A 5-month-old bitch of Pyrenean mountain dog with body weight of $30 \mathrm{~kg}$ was injured in a car incursion and sustained Salter-Harris type I femoral head fracture with three free fragments. Through cranio-lateral incision the cranial segment reduction was performed followed by fixation with three $0.8 \mathrm{~mm}$ Kirschner wires, remaining fragments stabilized with three $1.4 \mathrm{~mm}$ Kirschner wires. The remains of ligamentum capitis ossis femoris were removed. Ehmer bandage was applied postoperatively. After four weeks all wires were removed except $1.4 \mathrm{~mm}$ wire. Femoral head and acetabulum arthrosis are visible radiographically. Eight weeks post-surgical radiography showed hip displacement with clinical finding of limping, pain and crepitation on palpation of the hip joint. In this case, femoral head and neck ostectomy was indicated. Pre- and postoperative radiographs are shown on figure 2.

\section{Group B}

Case 3. AO: 32-A3

An 8-month-old bitch German hunting Terrier bitch was presented with a transverse fracture in femoral shaft. MIPO approach was performed for application of intramedullary Kirschner wire and string of pearls (SOP) plate and 5 screws. In a 4 weeks post-operative radiographic examination a good callus formation was found. Clinically the dog manifested limping (1/4). Pre- and post-operative radiographs are shown on figure 3.

\section{Case 4. AO: 32-C1}

A 3-year-old male German Shepard was referred with open spiral fracture in left femoral diaphysis associated with a free fragment. Using lateral approach $8 \mathrm{~mm}$ x $185 \mathrm{~mm}$ intramedullary interlocking nail was introduced with one screw proximal and two screws distal locking. Drainage was also established. Four weeks post-operative radiography revealed the beginning of bone healing. Eight weeks postoperatively radiography showed poor callus formation with complete restitution of function. Pre- and post-operative radiographs are shown on figure 4.

\section{Case 5. AO: 32-A3}

A 4-month-old male bitch of mongrel breed with body weight of $17.4 \mathrm{~kg}$ sustained a transverse fracture of right femoral diaphysis due to being hit by a horse. Using a lateral approach on diaphysis the $3.5 \mathrm{~mm}$ dynamic compression plate (DCP) with 8 screws was placed. Four weeks post-operative X-ray examination revealed moderate amount of callus formation, and clinical status showed clinical union. Pre- and post-operative radiographs are shown on figure 5.

\section{Group C}

\section{Case 6. AO: 33-C1}

A 3-year-old castrated American Stafford Terrier bitch with body weight of $23 \mathrm{~kg}$ was presented with transverse supracondylar, and spiral intracondylar metaphyseal fracture in right femur (Salter-Harris type II). Using a lateral approach to diaphysis and distal part of the femur, $3.5 \mathrm{~mm} \mathrm{leg} \mathrm{screw} \mathrm{was} \mathrm{placed} \mathrm{transcondylar} \mathrm{and} \mathrm{polyaxial} \mathrm{locking}$ system (PAX) 3.5 plate with 4 screws proximal and 3 distal from the fracture site. Four weeks postoperative radiography indicated poor amount of callus formation. The dog was actively putting pressure on the leg and the wound healing was completed in this time. Pre- and post-operative radiographs are shown on figure 6. 
Case 7. AO: 33-AI

A 1.5-year-old mongrel bitch with body weight of $7 \mathrm{~kg}$ sustained Salter-Harris type I fracture in distal epiphysis of left femur consequent to fall over suspended wire during running. Using lateral approach to distal femoral diaphysis, two Kirschner wires were introduced. Four weeks postoperative radiography showed good bone healing, and clinically complete function restitution after 8 weeks. Pre- and post-operative radiographs are shown on figure 7.

Case 8. AO: 33-A1

A 7-year-old male Yorkshire terrier with body weight of $1.5 \mathrm{~kg}$ was referred with Salter-Harris type II fracture in right distal femoral epiphysis due to fall from first floor balcony. Using lateral approach to distal femoral epiphysis two cross Kirschner wires $1.0 \mathrm{~mm}$ and $1.2 \mathrm{~mm}$ were introduced. Four weeks postoperative radiography revealed normal location of implants and the beginning of bone healing associated with no signs of limping clinically. Pre- and postoperative radiographs are shown on figure 8.
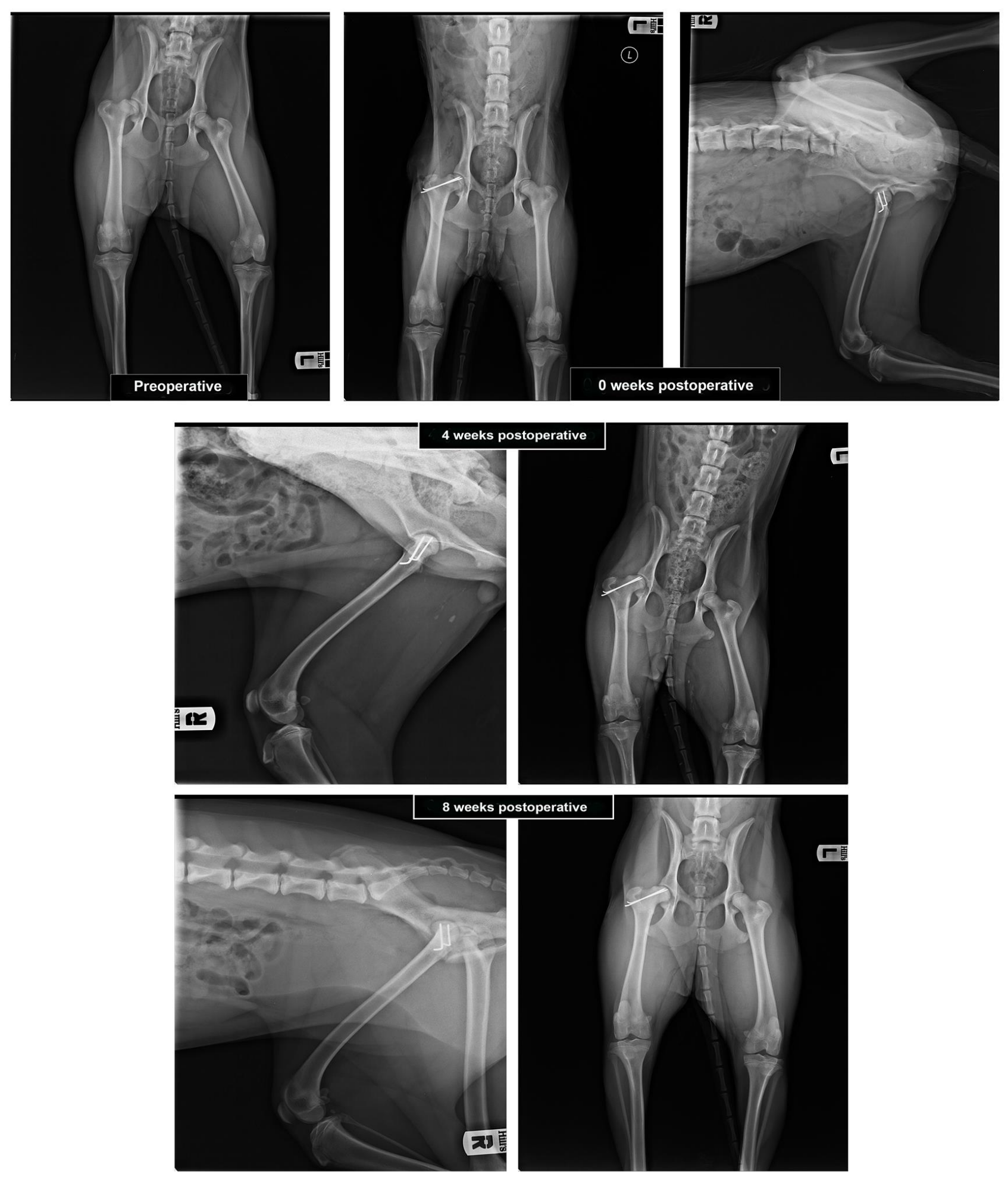

Figure 1. Pre- and postoperative radiographs of Salter-Harris type I femoral head fracture in dog. 

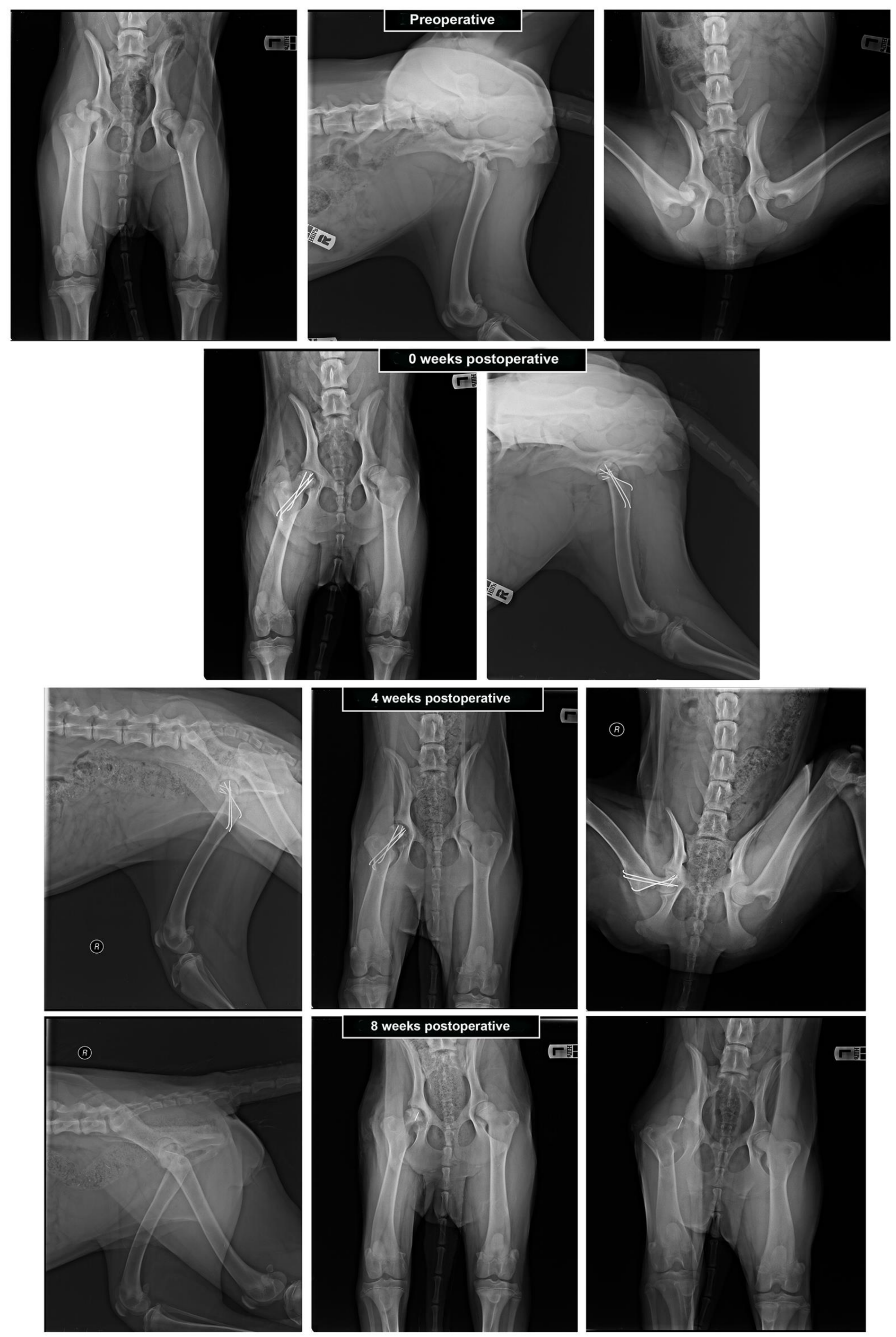

Figure 2. Pre- and postoperative radiographs of Salter-Harris type I femoral head fracture associated with three free fragments in dog. 

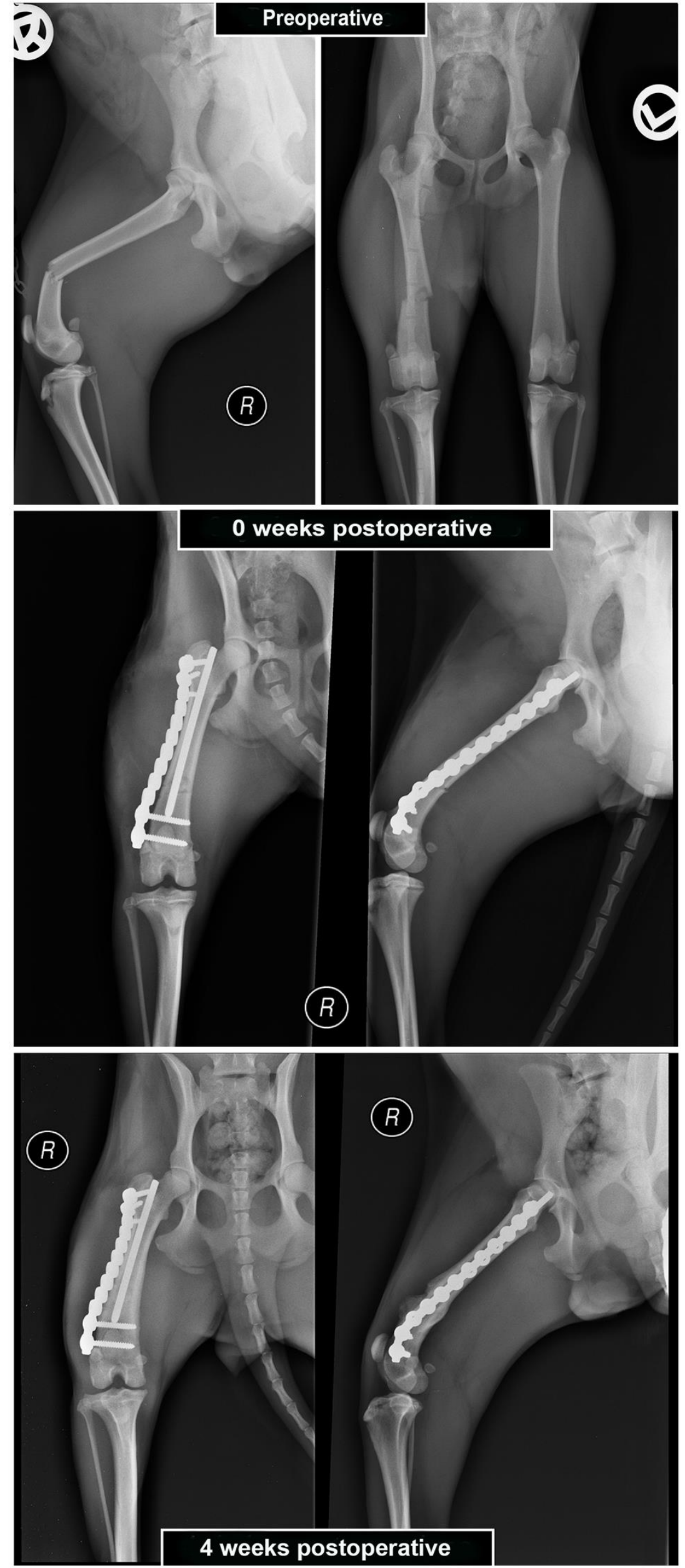

Figure 3. Pre- and postoperative radiographs of transverse right femoral diaphysis fracture in dog. 


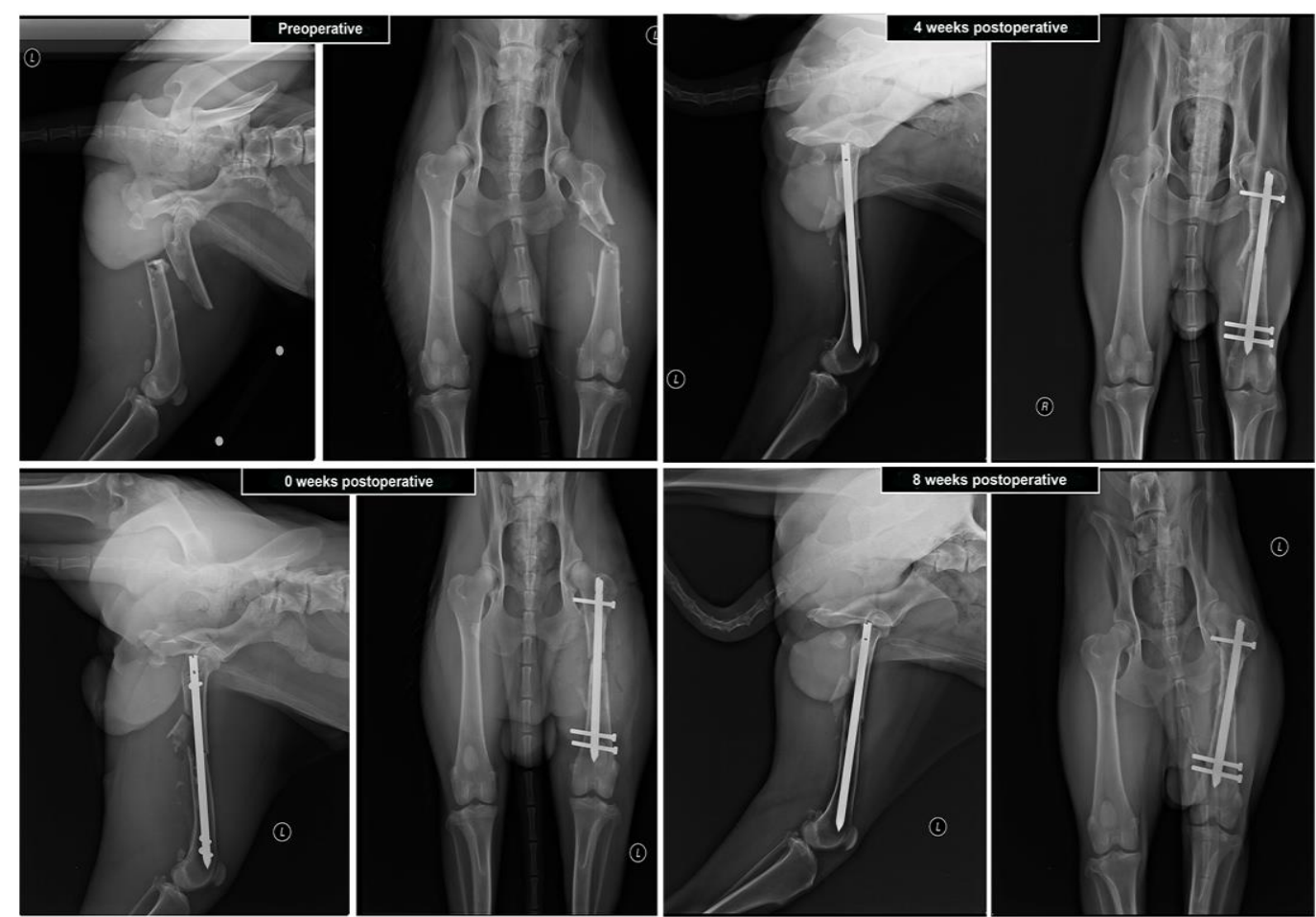

Figure 4. Pre- and postoperative radiographs of open spiral left femoral shaft fracture in dog.

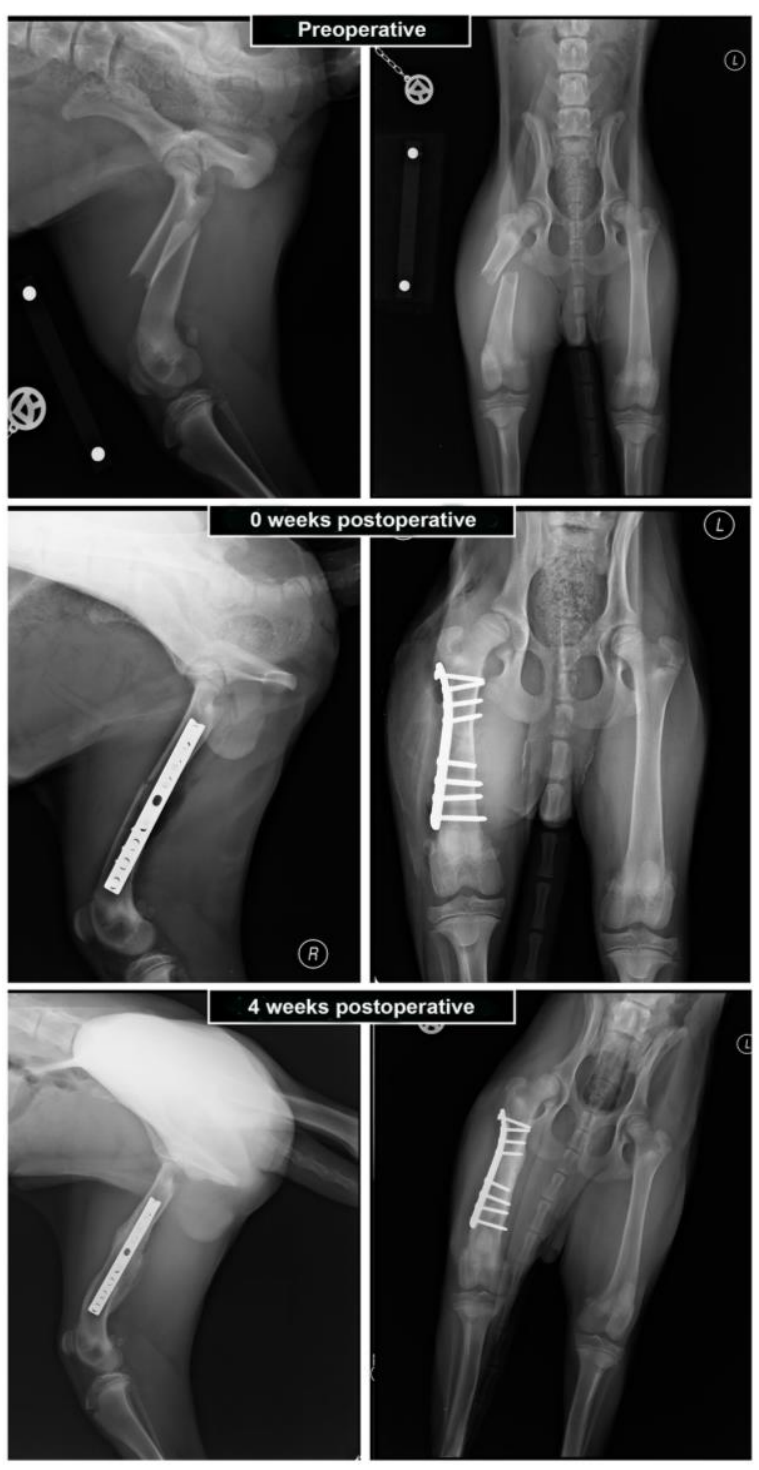

Figure 5. Pre- and postoperative radiographs of transverse right femoral shaft fracture in dog.
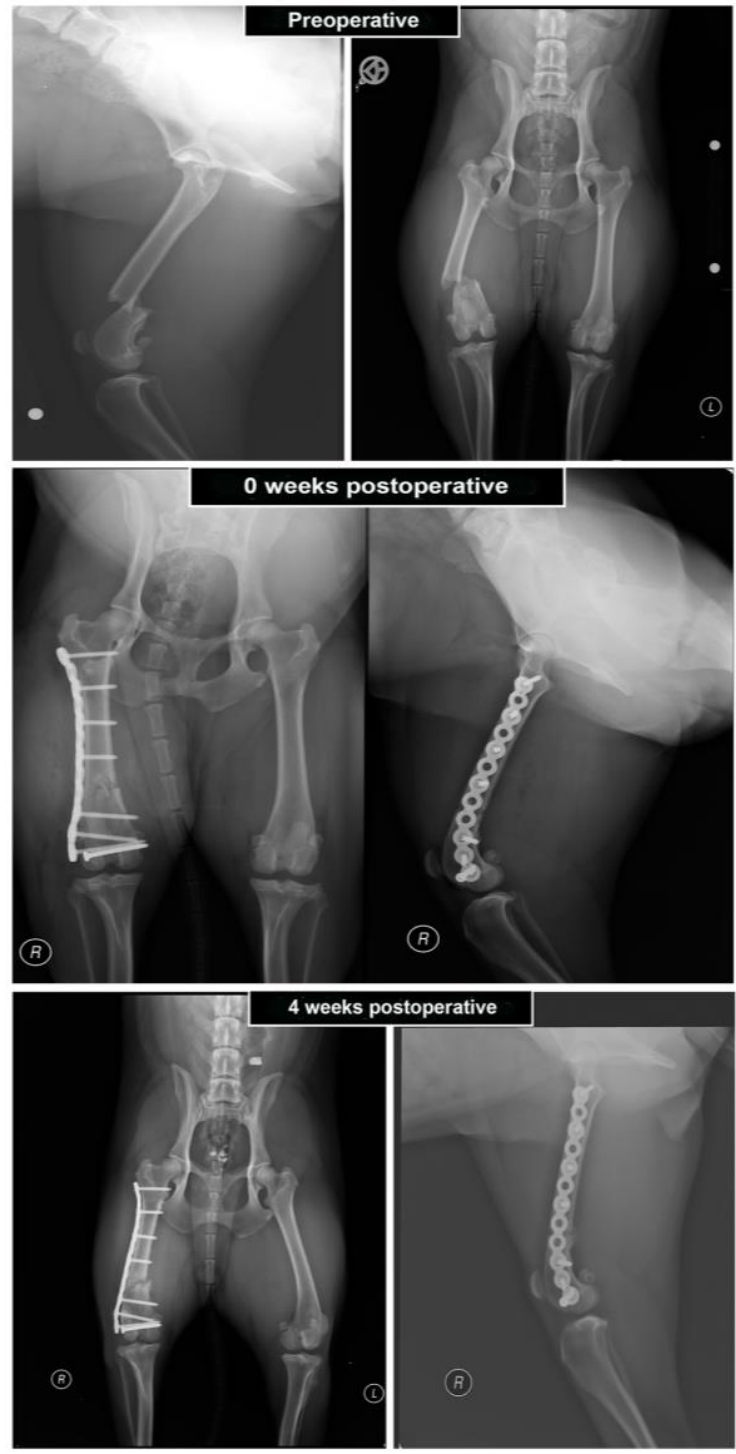

Figure 6. Pre- and postoperative radiographs of supracondylar transverse and metaphyseal fracture (Salter-Harris type II) of right femur in dog. 

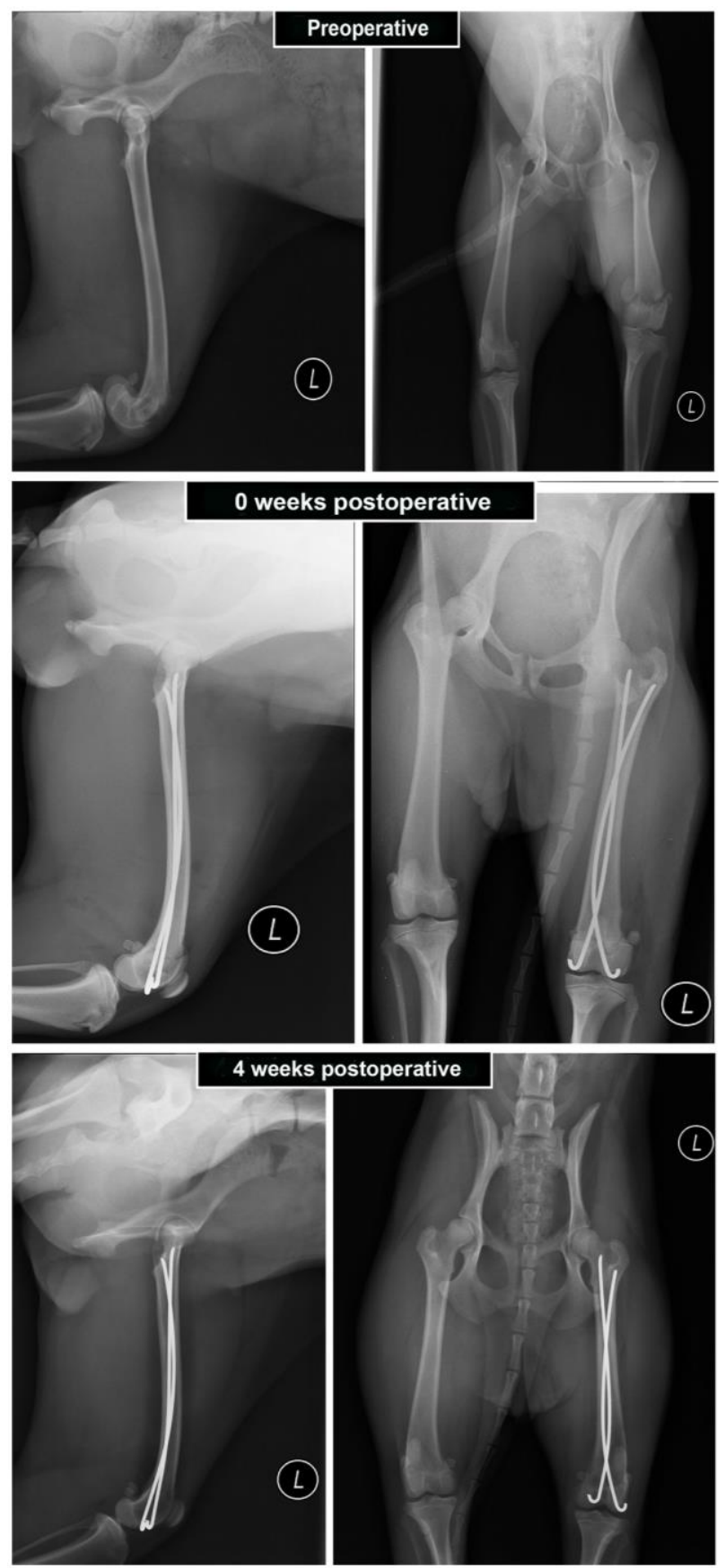

Figure 7. Pre- and postoperative radiographs of distal femoral epiphysis fracture (Salter-Harris type II) in dog.
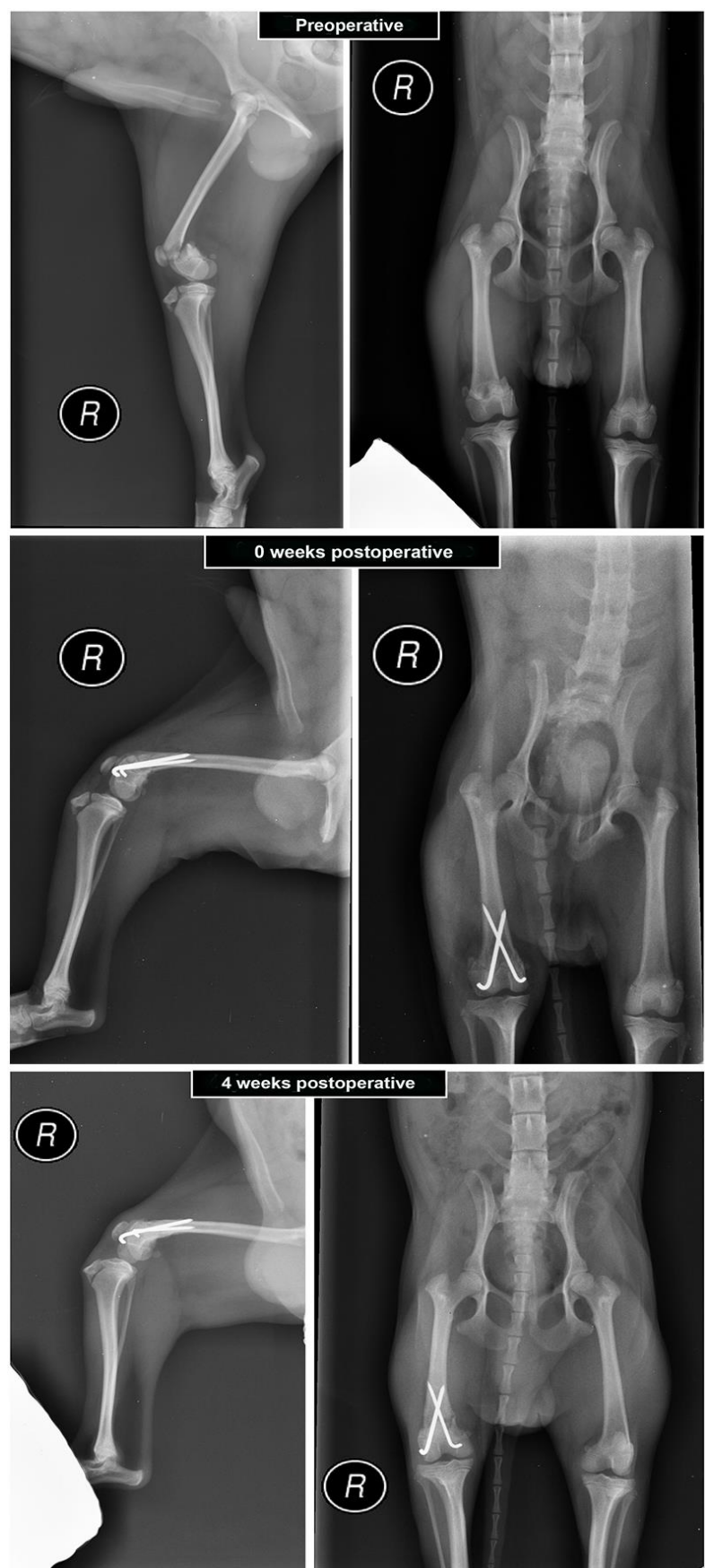

Figure 8. Pre- and postoperative radiographs of distal femoral epiphysis fracture (Salter-Harris type II) in dog.

\section{DISCUSSION}

The significance of femoral fractures in dogs and cats is high in comparison with other long bone fractures because $45 \%$ of fractures relates to femoral fractures. Closed fractures are the most frequent because of direct effect on the femur. Clinical examinations have been completing with radiography. Conservative management is practically abandoned because of poor results. Therefore, surgical treatment is a method of choice. Selection of surgical method depends on the fracture type, level and complexity, competence and available equipment as well. There are some adventages and disadvantages for each treatment method.

The most frequent of all proximal epiphyseal femoral fractures is metaphyseal fracture Salter-Harris type I (Guiot et al., 2012). In operating proximal epiphyseal femoral fractures, the most common method of choice is combination of Kirschner wires with leg screw or 2-3 Kirschner wires application. Femoral diaphyseal fractures can be stabilized by surgical application of external or internal fixation. Internal fixation can be performed by applying intramedullary wire, interlocking nail, various plates with screws, or cerclage rings and combining of all these methods (Beale, 2004). Bridging veterinary cuttable plates (VCP), minimally invasive plate osteosynthesis (MIPO) or open but do not touch (OBDNT) approach revealed to be the best choice in management of femoral shaft fractures in young dogs (Cabassu, 2019; Déjardin and Cabassu, 2004; Kowaleski, 2020; Sarran et al., 2007). Interlocking nail is another efficient implant 
for biological or anatomic osteosynthesis of comminuted femoral shaft fractures (Bellon and Mulon, 2011). Biological advantage and efficacy of this implant in the management of comminuted femoral shaft fractures had been evidenced (Horstman et al., 2004; Piorék et al., 2012; Déjardin et al., 2020). It is modified Küntscher nail with transverse openings designed for insertion of transcortical screws. Those screws increase strength against bending, rotation and compression forces. This system is cheaper than intramedullary wires combined with plate, but owning similar biomechanical ability coincidencely, this is an alternative to plates as mentioned before. (Piorék et al., 2012).

The complication rate is low, even $83 \%-96 \%$ of femoral fractures reductions have no complications (Guiot et al., 2012; Déjardin et al., 2020). The technique of interlocking nail application produces minimal disruption of surrounding soft tissue, due to small incision, thus diminishing the possibility of retarded or delayed bone union and fracture site infections. All specified advantages make interlocking nail a plausible method of choice (Horstman et al., 2004; Piorék et al., 2012; Déjardin et al., 2020). Epiphyseal fractures are often in young animals between 4 and 11 months of age, the most frequent is Salter-Harris type II respectively. The most common method of stabilization is application of Kirschner wires, slim Steinmann nails or Rush wires in cross mode. These fractures result as much as $83 \%$ of premature closure of the epiphysis. Supracondylar fractures are considered to be rare representing only $6 \%$ of all femoral fractures. These fractures can be treated by application of plates, leg screws, Kirschner wires, Rush wires, interlocking nails or external fixators. In elder dogs, the most common method for this type of fractures is plate application. Intraarticular unicondylar or bicondylar fractures represent $10 \%-15 \%$ of all distal epiphyseal femoral fractures. The stabilization in these cases can be accomplished using more Kirschner wires, leg screws or combination of these methods (Guiot et al., 2012).

The complications in femoral fracture operations include wound rupture, seroma formation, retreaded or delayed bone union, incision or bone infection, and hip and stifle joint arthritis or arthrosis in cases of epiphyseal fractures. According to experiences of the surgical team of veterinary clinic "Tierklinik Hollabrunn", the method preferred is intramedullary wires application associated with locking plate in cases of femoral shaft fractures. In this study, group B includes three cases of femoral shaft fractures managed by three different techniques. Radiography after 4 weeks in case number 5 (application of dynamic compression plate with 8 screws) revealed moderate amount of callus formation associated with complete restituted function. Comparing to Asma et al. (2014) study results showed discrepancy. The present study and Asma et al. (2014) study, have a lack of statistical significance due to small number of cases. According to available literature, numerous authors prefer intramedullary wires with the addition of minimally invasive plate osteosynthesis (Cabassu, 2019). This approach includes indirect method of fracture reduction by minimal incisions with intact periosteum. Some authors assume the use of intramedullary locking nail to be a method of choice providing the best results respectively (Brückner et al., 2016; Déjardin et al., 2020). Human medical studies support this attitude (Jain et al., 2004; Kesemenli et al., 2012; Ouyang et al., 2015; Duymus et al., 2019; Grubor et al., 2019). Each surgical procedure has a burden of certain percentage of complications. Taking into consideration biomechanical attributes of particular methods of bone fixation and predictable percentage of complications, it depends on the decision of every team dealing with operative treatment of femoral fractures to choose the method in which the team is the most competent and sufficiently equipped.

\section{DECLARATIONS}

\section{Competing interests}

The authors have declared that no competing interest exists.

\section{Author's contribution}

All authors participated equally in study design, data collection, data analysis, writing, and approving the final manuscript.

\section{REFERENCES}

Abd El Raouf M, Mekkawy NHM and AbdEl-Aal AM (2017): Femur fractures and treatment options in 20 dogs admitted to our clinic from January 2013 to December 2015. Iraqi Journal of Veterinary Science, 31 (2):117-122. DOI: https://doi.org/ 10.33899/ijvs.2017.145608

Asma B (2014). Osteo-synthesis use in dogs' femur fracture repair: An experimental and comparative study. World's Veterinary Journal, 4 (1):06-10. Available at: http://wvj.science-line.com/vol-4-no-1-mar-2014.html.

Beale B (2004). Orthopedic clinical techniques femur fracture repair. Clinical Techniques in Small Animal Practice, 19 (3):134-150. DOI: https://doi.org/10.1053/j.ctsap.2004.09.006

Bellon J and Mulon PY (2011). Use of a novel intramedullary nail for femoral fracture repair in calves: 25 cases (2008-2009). Journal of the American Veterinary Medical Association, 238 (11):1490-1496. DOI: https://doi.org/10.2460/javma.238.11.1490

Brückner M, Unger M and Spies M (2016). Early clinical experience with a newly designed interlocking nail system - Targon (®). Veterinary Surgery, 45 (6):754-763. DOI: https://doi.org/10.1111/vsu.12511

Cabassu J (2019). Minimally invasive plate osteosythesis using fracture reduction under the plate without intraoperative fluoroscopy to stabilize diaphyseal fractures of the tibia and femur in dogs and cats.Veterinary and Comparative Orthopaedics and Traumatology, 32 (06):475-478. DOI: $\underline{\text { https://doi.org/10.1055/s-0039-1693413 }}$ 
DeCamp CE, Johnston SA, Déjardin LM and Schaefer SL (2016). Brinker, Piermattei, and Flo's Handbook of Small Animal Orthopedics and Fracture Repair. $5^{\text {th }}$ ed. St. Louis: Saunders Elsevier, pp. 518-596. Available at: https://www.sciencedirect.com/book/9781437723649/brinker-piermatteiand-flos-handbook-of-small-animal-orthopedics-and-fracture-repair

Déjardin LM and Cabassu JP (2005). Femoral fractures in young dogs. AO Dialogue 3/08:39-43. Available at: https://issuu.com/aofoundation/docs/aodialogue $2008 \quad 3$

Déjardin LM, Perry KL, von Pfeil DJF and Guiot LP (2020). Interlocking nails and minimally invasive osteosynthesis. Veterinary Clinics of North America: Small Animal Practice, 50 (1):67-100. DOI: https://doi.org/10.1016/j.cvsm.2019.09.003

Duymus TM, Aydogmus S, Ulusoy İ, Kececi T, Adiyeke L, Dernek B and Mutlu S (2019). Comparison of intra- and extramedullary implants in treatment of unstable intertrochanteric fractures. Journal of Clinical Orthopaedics and Trauma, 10 (2):290-295. DOI: https://doi.org/10.1016/j.jcot.2018.04.003

Grubor P, Mitković M, Mitković M and Grubor M (2019). Comparison of biomechanical stability of osteosynthesis materials in long bone fractures. Medicinski Glasnik (Zenica), 16 (1): 88-92. DOI: https://doi.org/10.17392/985-19.

Guiot LP, Demianiuk RM and Déjardin LM (2012). Fractures of the Femur. In: Tobias KM, Johnston SA, editors. Veterinary Surgery Small Animal. $1^{\text {st }}$ ed. St. Louis: Saunders Elsevier, pp. 865-905. Available at: https://www.elsevier.com/books/veterinary-surgery-small-animal/tobias/978-14377-0746-5

Horstman CL, Beale BS, Conzemius MG and Evans R (2004). Biological Osteosynthesis Versus Traditional Anatomic Reconstruction of 20 LongBone Fractures Using an Interlocking Nail: 1994-2001. Veterinary Surgery, 33 (3): 232-237. DOI: https://doi.org/10.1111/j.1532950X.2004.04034.x

Jain P, Maini L, Mishra P, Upadhyay A and Agarwal A (2004). Cephalomedullary interlocked nail for ipsilateral hip and femoral shaft fractures. International Journal of the Care of the Injured, 35 (10): 1031-1038. DOI: https://doi.org/10.1016/j.injury.2003.09.039

Kesemenli CC, Tosun B and Kim NSY (2012). A comparison of intramedullary nailing and plate-screw fixation in the treatment for ipsilateral fracture of the hip and femoral shaft. Musculoskeletal Surgery, 96 (2): 117-124. DOI: https://doi.org/10.1007/s12306-012-0206-3

Kolar P, Schmidt-Bleek K, Schell H, Gaber T, Toben D, Schmidmaier G, Perka C, Buttgereit F and Duda GN (2010). The early fracture hematoma and its potential role in fracture healing. Tissue Engineering Part B: Reviews, 16 (4): 427-434. DOI: https://doi.org/10.1089/ten.teb.2009.0687

Kowaleski MP (2020). Minimally invasive osteosynthesis techniques of the femur. Veterinary Clinics of North America: Small Animal Practice, 50 (1):155-182. DOI: https://doi.org/10.1016/j.cvsm.2019.09.002

Ouyang X, Wang JR, Hong SD, Xin F, Wang L, Yang XW and Wang J (2015). Interlocking intramedullary nails in fracture treatment. Cell Biochemistry and Biophysics, 73 (1):261-265. DOI: https://doi.org/10.1007/s12013-015-0622-8

Pan Z, Pan J, Wang H, Yu Z, Li Z, Yang W, Li J, Zhu Q and Luo Z (2019). Healing physiology following delayed surgery for femoral midschaft fracture caused by high-energy injury: an in vivo study in dogs. Journal of International Medical Research, 47 (10):5155-5173. DOI: https://doi.org/10.1177/0300060519860704

Perren SM (2002). Evolution of the internal fixation of long bone fractures. The scientific basis of biological internal fixation: choosing a new balance between stability and biology. The Journal of Bone and Joint Surgery. British Volume, 84 (8):1093-1110. DOI: https://doi.org/10.1302/0301$\underline{620 X .84 B 8.13752}$

Piórek A, Adamiak Z, Matyjasik H and Zhalniarovich Y (2012). Stabilization of fractures with the use of veterinary interlocking nails. Pakistan Veterinary Journal, 32 (1):10-14. Available at: http://www.pvj.com.pk/

Rüedi TP and Murphy WM (2000). AO Principles of fracture management. Stuttgart, New York: Thieme, pp. 445-473.

Sarrau S, Meige F and Autefage A (2007). Treatment of femoral and tibial fractures in puppies by elastic plate osteosynthesis. Veterinary and Comparative Orthopaedics Traumatology, 20 (1):51-58. DOI: https://10.1055/s-0037-1616588

Schell H, Duda GN, Peters A, Tsitsilonis S, Johnson KA and Schmidt-Bleek K (2017). The haematoma and its role in bone healing. Journal of Experimental Orthopaedics, 4: 5. DOI: https://doi.org/10.1186/s40634-017-0079-3 